\title{
Single oral dose of cefaclor for the treatment of infections with penicillinase-producing strains of Neisseria gonorrhoeae
}

\author{
THELMA E TUPASI, OFELIA V CALUBIRAN, AND CLEOTILDE A TORRES \\ From the Infectious Disease Section, Department of Medicine, College of Medicine, University of the \\ Philippines, Manila, Philippines
}

SUMMARY A single oral dose of $\mathbf{3} \mathrm{g}$ cefaclor was effective in the treatment of uncomplicated $\stackrel{\$ क}{=}$. gonococcal infection in women due to penicillinase-producing strains of Neisseria gonorrhoeae $e_{\infty}^{j}$ (PPNG). Cefaclor was equally active in vitro against both PPNG (MIC range, 0.01-1.0 $\mu \mathrm{g} / \mathrm{ml}) \dot{\omega}$ and non-PPNG strains (MIC range, $0 \cdot 005-2 \cdot 0 \mu \mathrm{g} / \mathrm{ml}$ ). As empirical treatment cefaclor was $\vec{\nabla}$ effective in 53 of $57(93 \%)$ patients compared with ampicillin, to which only 37 of $53(69 \cdot 8 \%)_{\circ}^{\circ}$ patients responded. This difference was attributed to the $40 \%$ incidence of PPNG in the patients? studied; as expected, such patients responded poorly to ampicillin.

\section{Introduction}

Cefaclor is an acid-stable semisynthetic cephalosporin which differs from its parent substance, cephalexin, in the substitution of a chloro group in the 3 position. Like cephalexin, cefaclor is absorbed orally but has the advantage of greater in-vitro activity against pathogens, particularly Haemophilus influenzae and Neisseria gonorrhoeae and their $\beta$-lactamase-positive strains. ${ }^{12}$ Compared with other cephalosporins cefaclor was second only to cefuroxime in its activity against $N$ gonorrhoeae. ${ }^{2}$

Preliminary studies of the treatment of gonococcal urethritis in men have shown cefaclor to be effective in doses ranging from $2-4 \mathrm{~g}$ with or without probenecid. ${ }^{3}$ Its efficacy in infections with penicillinaseproducing $N$ gonorrhoeae (PPNG) has not yet been studied. The purpose of this study was to determine the efficacy of cefaclor in the treatment of uncomplicated gonococcal infections in women, particularly those due to PPNG. The results of empirical treatment of gonococcal infection with this drug were compared to those with the standard oral dose of ampicillin. Minimum inhibitory concentrations (MIC) of cefaclor, ampicillin, and penicillin against the isolates of $N$ gonorrhoeae were measured and correlated with the response to treatment.

Address for reprints: $\mathrm{Dr}$ T E Tupasi, Department of Medicine, College of Medicine, University of the Philippines, Pedro Gil Street, Manila, Philippines

Accepted for publication 7 November 1981

\section{Patients and methods}

STUDY DESIGN
Prostitutes with uncomplicated gonococcal infection confirmed by culture on screening volunteered to join the study after the protocol had been explained. Written informed consent was obtained and theo study was conducted in accordance with the guidelines for human experimentation of the Declaration of Helsinki and the Committee on Research, Ethics, and Development of the UP Health Sciences Center

Pretreatment culture specimens were obtained. from the cervix, urethra, rectum, and pharynx, after which patients were assigned to either treatmento group by random allocation using a table of random numbers.

The patients were admitted to the clinic for three days after treatment to observe for possible sideo effects and, more importantly, to preclude reinfec- $D$ tion before test-of-cure cultures were obtained on the second and third post-treatment days. Only patients with confirmed gonococcal infection based on $a^{\circ}$ positive pretreatment culture result were evaluated. 0 Treatment was considered to have failed if post-treat $-\frac{N}{\omega}$ ment culture results were still positive for $N$ gonor-क rhoeae.

\section{TREATMENT REGIMENS}

Treatment consisted of a single oral dose of either $3 \stackrel{5}{\mathrm{~g}}$ cefaclor or $3.5 \mathrm{~g}$ ampicillin with $1 \mathrm{~g}$ probenecid Patients who were randomly allocated to the ampi $\frac{\text { 아 }}{\text { }}$ cillin group and from whose pretreatment cultures? PPNG were subsequently isolated were retreate\& 
with spectinomycin $2 \mathrm{~g}$ intramuscularly after posttreatment culture results were obtained and immediately before discharge.

\section{STATISTICAL ANALYSIS}

Fisher's exact test and the $\chi^{2}$ test with Yates's correction were used.

\section{BACTERIOLOGICAL TECHNIQUES}

$N$ gonorrhoeae was isolated and identified according to standard procedures. ${ }^{4}$ Penicillinase production by the isolated strains of $N$ gonorrhoeae was determined by the rapid iodometric test ${ }^{5}$ and confirmed by the chromogenic cephalosporin method of O'Callaghan. ${ }^{6}$ The MICs of cefaclor, ampicillin, and penicillin were determined by the agar dilution method using standard procedures. ${ }^{7}$

\section{OTHER LABORATORY INVESTIGATIONS}

Complete blood cell count, urine analysis, and serum alanine aminotransferase (ALT), blood urea nitrogen, and serum creatinine concentrations were determined before treatment and 24 hours later.

\section{Results}

\section{STUDY POPULATION}

A total of 122 patients were initially enrolled in the study; those in each treatment group were comparable for age, weight, and sexual exposure. Since penicillinase production of the infecting strain could not be determined from the pretreatment culture at the time of the patient's inclusion into the study, the patients were not grouped according to this criterion. Thus, using random allocation, it was solely by chance that more patients with PPNG strains were assigned to the cefaclor treatment group.

Twelve patients, including four given cefaclor and eight given ampicillin, were excluded from the study because of negative pretreatment culture results. Interestingly, in one such patient given cefaclor with a negative pretreatment culture result, post-treatment cultures from the cervix and rectum subsequently gave a heavy growth of PPNG. Despite the precautions taken against reinfection during the study, this could not be totally excluded, as the patient may have left the clinic without the knowledge of the clinic staff.

The ages of the remaining 110 patients ranged from 15 to 34 years with a mean of 20 years, and weights ranged from $36 \cdot 3 \mathrm{~kg}$ to $61 \cdot 3 \mathrm{~kg}$ with a mean of $45 \cdot 5 \mathrm{~kg}$. Thirty-eight of $110(34 \cdot 5 \%)$ patients were symptomatic; 44 patients were infected with PPNG and 66 with non-PPNG strains of $N$ gonorrhoeae. Twenty-seven of the former and 30 of the latter were treated with cefaclor and the remainder received ampicillin.
TABLE I Results of treatment in 122 patients with uncomplicated gonococcal infection

\begin{tabular}{|c|c|c|c|}
\hline \multirow{2}{*}{$\begin{array}{l}\text { Treatment } \\
\text { outcome }\end{array}$} & \multicolumn{3}{|c|}{ No of patients harbouring strains of: } \\
\hline & $P P N G$ & Non-PPNG & Total \\
\hline \multicolumn{4}{|c|}{ Cefaclor $(n=61)^{*}$} \\
\hline Response & 27 & 26 & 53 \\
\hline Failure & 0 & 4 & 4 \\
\hline Total & & & 57 \\
\hline \multicolumn{4}{|c|}{ Ampicillin $(n=61)^{*}$} \\
\hline Response & 1 & 36 & 37 \\
\hline Failure & 16 & 0 & 16 \\
\hline Total & & & 53 \\
\hline
\end{tabular}

*Of the two treatment groups, four and eight patients were excluded from the analysis as their pretreatment culture results were negative for $N$ gonorrhoeae

PPNG = penicillinase-producing $N$ gonorrhoeae; $n=$ No of patients treated

\section{TREATMENT}

Fifty-three of the $57(93 \%)$ patients treated with cefaclor responded to treatment compared with 37 of $53(69 \cdot 8 \%)$ patients treated with ampicillin. This difference was statistically significant $\chi_{i}^{2}=8 \cdot 416$, $\mathrm{P}<0.01)$. Of patients with PPNG infections, all 27 responded to cefaclor while 16 of $17(94 \cdot 1 \%)$ failed to respond to ampicillin (table I). The single patient who responded to ampicillin had only a few colonies of PPNG in her pretreatment culture from the urethra; after treatment no organisms were cultured from this site. In patients with non-PPNG infections the therapeutic response was significantly better with ampicillin $(P=0.038$ by Fisher's exact test) since no failure was noted with this drug compared with four failures out of $30(13 \cdot 3 \%)$ with cefaclor.

\section{MINIMUM INHIBITORY CONCENTRATIONS}

The correlation between the treatment response with cefaclor and the corresponding MICs of cefaclor for the infecting strains are shown in table II. Four treatment failures occurred among patients infected with

TABLE II Minimum inhibitory concentrations of infecting $N$ gonorrhoeae strain from patients treated with cefaclor in relation to treatment failures

\begin{tabular}{|c|c|c|c|c|}
\hline \multirow{3}{*}{$\begin{array}{l}M I C \\
(\mu g / m l)\end{array}$} & \multicolumn{4}{|c|}{ No of patients harbouring strains of: } \\
\hline & \multicolumn{2}{|l|}{$P P N G$} & \multicolumn{2}{|c|}{ Non-PPNG } \\
\hline & Treated & Failed & Treated & Failed \\
\hline$\leqslant 0.025$ & 1 & 0 & & \\
\hline $0 \cdot 1$ & 3 & 0 & 4 & 1 \\
\hline $0 \cdot 2$ & & & 7 & 0 \\
\hline 0.5 & 15 & 0 & 14 & 1 \\
\hline $1 \cdot 0$ & 6 & 0 & 4 & 2 \\
\hline$\geqslant 2 \cdot 0$ & & & 1 & 0 \\
\hline ND & 2 & 0 & 0 & 0 \\
\hline Total & 27 & 0 & 30 & 4 \\
\hline
\end{tabular}

PPNG = penicillinase-producing $N$ gonorrhoeae $;$ ND $=$ not done 
non-PPNG strains; of these, two had MICs of $1.0 \mu \mathrm{g} / \mathrm{ml}$, one of $0.5 \mu \mathrm{g} / \mathrm{ml}$, and one of $0.1 \mu \mathrm{g} / \mathrm{ml}$. Two of $25(8 \%)$ patients whose infecting strains had MICs of $\leqslant 0.5 \mu \mathrm{g} / \mathrm{ml}$ cefaclor failed to respond compared with two of five $(40 \%)$ with MICs of $\geqslant 1.0 \mu \mathrm{g} / \mathrm{ml}$ cefaclor; this difference was not statistically significant $(P=0.019$ by Fisher's exact test). Sixteen patients who failed to respond to ampicillin had infecting strains of PPNG with MICs ranging from $4 \cdot 0-\geqslant 64 \mu \mathrm{g} / \mathrm{ml}$ of ampicillin.

The MICs of cefaclor, ampicillin, and penicillin for the isolates are shown in table III. The MICs of the three antibiotics were not determined in a few of the isolates, which could not be retrieved from the stock cultures. The MIC range of cefaclor for PPNG strains was $0 \cdot 01-1 \cdot 0 \mu \mathrm{g} / \mathrm{ml}$ with $84 \cdot 2 \%$ of isolates inhibited by $0.5 \mu \mathrm{g} / \mathrm{ml}$ and was similar to that for non-PPNG strains at $0 \cdot 005-2 \cdot 0 \mu \mathrm{g} / \mathrm{ml}$ with $87 \cdot 1 \%$ of isolates inhibited by $0.5 \mu \mathrm{g} / \mathrm{ml}$. Cefaclor was slightly more active in vitro than ampicillin and penicillin against non-PPNG strains; the ampicillin MIC range was $0 \cdot 05-8 \cdot 0 \mu \mathrm{g} / \mathrm{ml}$ with $79 \%$ of isolates inhibited by $0.5 \mu \mathrm{g} / \mathrm{ml}$ while the penicillin MIC range was $0.01-4.0 \mu \mathrm{g} / \mathrm{ml}$ with $75.4 \%$ of isolates inhibited by $0.5 \mu \mathrm{g} / \mathrm{ml}$. The PPNG strains were uniformly resistant to ampicillin and penicillin with MIC ranges of $4 \cdot 0-\geqslant 64 \mu \mathrm{g} / \mathrm{ml}$ and $16 \cdot 0-\geqslant 64 \mu \mathrm{g} / \mathrm{ml}$ respectively.

\section{SIDE EFFECTS}

Three of $57(5 \cdot 3 \%)$ patients given cefaclor had side effects of dizziness (one) and dizziness, headache,

TABII: III Cumulative percentage of isolates inhibited by increasing concentrations of cefaclor, ampicillin, and penicillin

\begin{tabular}{|c|c|c|c|c|c|c|}
\hline \multirow[b]{3}{*}{$\begin{array}{l}M I C \\
(\mu g / m l)\end{array}$} & \multicolumn{6}{|c|}{ \% of isolates inhibited by: } \\
\hline & \multicolumn{2}{|c|}{ Cefaclor } & \multicolumn{2}{|c|}{ Ampicillin } & \multicolumn{2}{|c|}{ Penicillin } \\
\hline & $P P N G$ & $\begin{array}{l}\text { Non- } \\
P P N G\end{array}$ & $P P N G$ & $\begin{array}{l}\text { Non- } \\
P P N G\end{array}$ & $P P N G$ & $\begin{array}{l}\text { Non- } \\
\text { PPNG }\end{array}$ \\
\hline$\leqslant 0 \cdot 005$ & & $1 \cdot 6$ & & & & \\
\hline 0.01 & $2 \cdot 6$ & $1 \cdot 6$ & & & & $7 \cdot 7$ \\
\hline 0.02 & $5 \cdot 3$ & $4 \cdot 8$ & & & & $10 \cdot 8$ \\
\hline 0.05 & $5 \cdot 3$ & $11 \cdot 3$ & & $6 \cdot 4$ & & $26 \cdot 2$ \\
\hline 0.1 & $31 \cdot 6$ & $38 \cdot 7$ & & $37 \cdot 1$ & & $33 \cdot 8$ \\
\hline $0 \cdot 2$ & $36 \cdot 8$ & $58 \cdot 1$ & & $64 \cdot 5$ & & $46 \cdot 2$ \\
\hline 0.5 & $84 \cdot 2$ & $87 \cdot 1$ & & $79 \cdot()$ & & $75 \cdot 4$ \\
\hline 1.0 & 100 & $98 \cdot 4$ & & $95 \cdot 2$ & & $87 \cdot 7$ \\
\hline $2 \cdot 0$ & & 100 & & 98.4 & & 95.4 \\
\hline $4 \cdot 0$ & & & $2 \cdot 7$ & $98 \cdot 4$ & & 100 \\
\hline $8 \cdot 0$ & & & $8 \cdot 1$ & $1(0)$ & & \\
\hline $16 \cdot 0$ & & & $21 \cdot 6$ & & $8 \cdot 1$ & \\
\hline $32 \cdot 0$ & & & $4(1) \cdot 5$ & & $43 \cdot 2$ & \\
\hline$\geqslant 64 \cdot 0$ & & & 10() & & 100 & \\
\hline No tested & 38 & 62 & 37 & 62 & 37 & 65 \\
\hline $\begin{array}{l}\text { No not } \\
\text { tested* }\end{array}$ & 6 & 4 & 7 & 4 & 7 & 1 \\
\hline
\end{tabular}

*Isolates not retrieved from stock cultures for MIC determination PPNG = penicillinase-producing.$\perp$ gonorrhoe'ue and nausea (two). In contrast, only one of $53(1 \cdot 9 \%)$ patients given ampicillin complained of dizziness. Ten patients treated with cefaclor showed changes in $\frac{\mathrm{O}}{\mathrm{N}}$ blood analysis (eosinophilia in six, leucopenia in two, leucocytosis in one, and a mildly raised ALT con- $\overline{\bar{N}}$ centration in one) compared with 14 treated with ampicillin (eosinophilia in seven, leucopenia in three, leucocytosis in two, and a mildly raised ALT concentration in two).

\section{Discussion}

With the recently reported isolation of a spectino- $\overrightarrow{\vec{C}}$ mycin-resistant strain of $P_{P N G}{ }^{8}$ an appraisal of the efficacy of the cephalosporins as an alternative $\stackrel{\text { of }}{=}$. treatment for gonococcal infection has become imperative. Despite earlier discouraging results of the $\underset{\omega}{\omega}$ treatment of gonorrhoea with older cephalosporins, $\vec{\overrightarrow{ }}$ such as cephaloridine, cefazolin, and cephalexin, ${ }^{9-12}$ oे newer congeners (notably cefuroxime and cefamandole) and a cephamycin, cefoxitin, have shown excellent in-vitro activity against $N$ gonorrhoeae. ${ }^{13} \subseteq$ Cefuroxime and cefoxitin have been highly effective $\stackrel{\bar{\sigma}}{\vec{D}}$ in the treatment of gonococcal infections, including $\vec{\theta}$ those due to PPNG. ${ }^{414}$ In addition to these drugs, $\infty$ our study shows that cefaclor, an oral cephalosporin, has excellent in-vitro activity against $N$ gonorrhoeae and was effective at a dose of $3 \mathrm{~g}$ in the treatment of uncomplicated gonococcal infections in women particularly those due to PPNG. Its oral route of administration is an important advantage over $\stackrel{\perp}{\varrho}$ cefuroxime and cefoxitin, which may make it more $\overrightarrow{\overrightarrow{0}}$ acceptable to patients. As empirical treatment before 3 the results of tests for penicillinase production of the $\bar{P}$ infecting strain were known, cefaclor was more? efficacious than ampicillin $(93 \%$ responded to of cefaclor compared with $69 \cdot 8 \%$ to ampicillin). This significant difference $\left(\chi_{1}^{2}=8 \cdot 416, \mathrm{P}<0.01\right)$ is 3 attributed to the $40 \%$ incidence of PPNG infections in the patients studied. As expected, such patients responded poorly to $\beta$-lactamase-sensitive drugs like ampicillin and penicillin.

The treatment failure rate among patients infected $\frac{7}{0}$ with non-PPNG strains was $13 \cdot 3 \%$ with cefaclor compared with zero failure with ampicillin. In-vitro on data suggest that cefaclor should be as effective as $\mathrm{N}$ ampicillin, so that the significant difference $\mathcal{N}$ $\left(\mathrm{P}=0.038\right.$ by Fisher's exact test) in the treatment ${ }^{\omega}$ results might be attributed to differences in the pharmacokinetics of the two drugs, most likely enhanced by the concomitant administration of $\Phi$ probenecid with ampicillin. Pharmacokinetic studies ? indicate that while cefaclor is rapidly absorbed in the gastrointestinal tract, it is cleared more rapidly than $\underset{\mathbb{D}}{\vec{D}}$ cephalexin from the serum ${ }^{15}$ and has a half-life of $\frac{?}{\mathbb{D}}$ 0.76 hours after a $\mathrm{l}-\mathrm{g}$ dose with no detectable con- $\mathrm{a}$ 
centrations six hours later. ${ }^{16}$ Conceivably, probenecid given with cefaclor in the treatment of gonococcal infection may ensure higher and prolonged concentrations of cefaclor. This potential benefit remains to be determined.

This project was supported by the National Research Council of the Philippines and the Eli Lilly Co.

\section{References}

1. Silver MS, Counts GW, et al. Comparison of in-vitro antibacterial activity of the three oral cephalosporins: cefaclor, cephalexin and cephaloridine. Antimicrob Agents Chemother 1977; 12:591-6

2. Hall WH, Schierl EA, et al. Comparative susceptibility of penicillinase-positive and negative Neisseria gonorrhoeue to 30 antibiotics. Antimicrob Agents Chemother 1979; 15: 562-7.

3. Spagna VA, Perkins RL, et al. Successful treatment with cefaclor of gonococcal urethritis in men. Sex Transm Dis 1979; 6:211-3.

4. Tupasi TE, Crisologo LB, et al. Single-dose therapy in 562 cases of uncomplicated gonorrhea in confined female cases. Proceedings of the 11th ICC and the 19th ICAAC American Society for Microbiology. Current Chemotherapy and Infectious Diseases 1980; 2:1270-2.

5. Catlin BW. Iodometric detection of Hemophilus influenzae beta-lactamase: rapid presumptive test for ampicillin resistance. Antimicrob Agents Chemother 1975; 7:265-70.
6. O'Callaghan CB, Kirby SM, Morris A, Shingler AH. Correlation between hydrolysis of the lactam bond of cephalosporin nucleus and expulsion of the 3 substituent. J Bacteriol 1972; 110:988-91.

7. Biddle JW, Swenson JM, Thornsberry C. Disc agar diffusion antimicrobial susceptibility test with $\beta$-lactamase-producing Neisseria gonorrhoeae. J Antibiot 1978;31:352-7.

8. Anonymous. Spectinomycin-resistant penicillinase-producing Neisseria gonorrhoeae. Morbidity and Mortality Weekly Report 1981;30:221.

9. Oller LZ, Smith HG, Marshall MJ. Cephaloridine and cephalexin in venereological practice. Postgrad Med J 1970; 46 suppl: 99-102.

10. Willcox RR, Woodcock KS. Cephalexin in the oral treatmen of gonorrhoea by a double-dose method. Postgrad Med J 1970;46 suppl:103-6.

11. Karney WW, Turck M, Holmes KK. Cefazolin in the treatment of gonorrhea. J Infect Dis 1973; 128 suppl:399-402.

12. Nelson M. Cefazolin in the treatment of uncomplicated gonorrhea in men. J Infect Dis 1973; 128 suppl: 404-6.

13. Barry AL, Thornsberry C, Jones RN, Fuchs PC, Gavan TL, Gerlach EH. Cefuroxime, an in-vitro comparison with six other cephalosporins. Proc $R$ Soc Med 1977; 70 suppl:63-71.

14. Berg SW, Kilpatrick ME, Harrison WO, McCutchan JA Cefoxitin as a single-dose treatment for urethritis caused by penicillinase-producing Neisseria gonorrhoeae. N Engl J Med 1979; 301:509-11.

15. Wise R, Andrews JM, Dean S, Welling PG, Kendall MJ. A pharmacological and in-vivo comparison of three oral cephalosporins. J Antimicrob Chemother 1979;5:601-7.

16. Hodges GR, Liu C, Hinthorn R, Harms JL, Dworzack DI. Pharmacological evaluation of cefaclor in volunteers. Antimicrob Agents Chemother 1978; 14:454-6. 